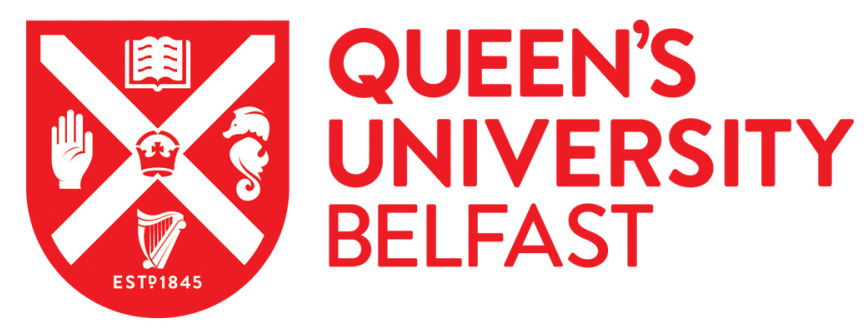

\title{
Teachers observing classroom communication: An application of the Communicating Supporting Classroom Observation Tool for children aged 4-7 years
}

Law, J., Tulip, J., Stringer, H., Cockerill, M., \& Dockrell, J. (2019). Teachers observing classroom

communication: An application of the Communicating Supporting Classroom Observation Tool for children aged 4-7 years. Child Language Teaching and Therapy, 35(3), 203-220. https://doi.org/10.1177/0265659019869792

Published in:

Child Language Teaching and Therapy

Document Version:

Peer reviewed version

Queen's University Belfast - Research Portal:

Link to publication record in Queen's University Belfast Research Portal

Publisher rights

(c) 2019 The Authors. This work is made available online in accordance with the publisher's policies. Please refer to any applicable terms of use of the publisher.

\section{General rights}

Copyright for the publications made accessible via the Queen's University Belfast Research Portal is retained by the author(s) and / or other copyright owners and it is a condition of accessing these publications that users recognise and abide by the legal requirements associated with these rights.

Take down policy

The Research Portal is Queen's institutional repository that provides access to Queen's research output. Every effort has been made to ensure that content in the Research Portal does not infringe any person's rights, or applicable UK laws. If you discover content in the

Research Portal that you believe breaches copyright or violates any law, please contact openaccess@qub.ac.uk. 


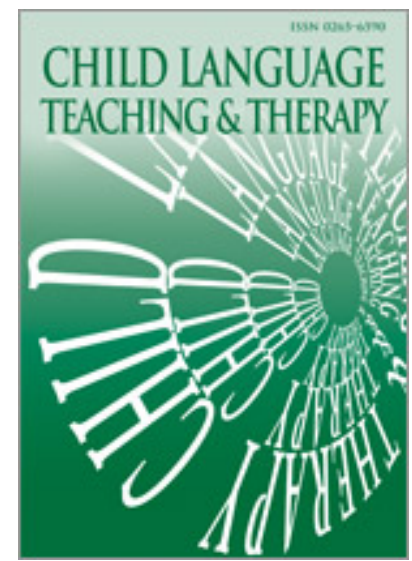

\section{Teachers observing classroom communication: An application of the Communicating Supporting Classroom Observation Tool for children aged 4-7 years.}

\begin{tabular}{|c|l|}
\hline Journal: & Child Language Teaching and Therapy \\
\hline Manuscript ID & CLT-18-0038.R3 \\
\hline Manuscript Type: & Original Manuscript \\
\hline Keywords: & $\begin{array}{l}\text { Communication, language, interaction, teacher, classroom, audit, early } \\
\text { years, CSCOT }\end{array}$ \\
\hline Abstract: & $\begin{array}{l}\text { Background } \\
\text { "Teacher talk" is likely to have a considerable bearing on the child's } \\
\text { learning but measuring the communication environment in the classroom } \\
\text { can present challenges. One tool which does this is the Communication } \\
\text { Supporting Classroom Observation Tool (CSCOT). Initial use suggested } \\
\text { that it was valid and reliably used by specialists (psychologists and } \\
\text { speech and language therapists) and SENCOs. A key question is whether } \\
\text { it can be used routinely by classroom teachers and whether results } \\
\text { coincide with those in earlier studies. }\end{array}$ \\
$\begin{array}{l}\text { Method } \\
\text { CSCOT observations were carried out by teachers in 33 schools (32 } \\
\text { Reception classrooms, 25 in Year 1 and 25 in Year 2) in two local } \\
\text { afterwards to reflect on their experiences using the tool. }\end{array}$ \\
$\begin{array}{l}\text { Results asked } \\
\text { Scores were in line with those in earlier studies and were consistently } \\
\text { higher on all dimensions for reception compared to Year 2, but there was } \\
\text { no difference between other year groups. Results were mostly consistent } \\
\text { with the original studies. Language learning environment was higher } \\
\text { relative to both language learning opportunities and interactions across } \\
\text { all years (which again did not differ). There was a moderate interaction } \\
\text { between language learning environment where scores were significantly } \\
\text { higher in the Reception group and lower in the Year } 2 \text { group. Teachers } \\
\text { supported the use of the CSCOT in their feedback, suggesting that } \\
\text { CSCOT was easy to use and useful in informing practice. }\end{array}$ \\
\hline
\end{tabular}


Conclusions

The CSCOT clearly has utility as a starting point in auditing classroom communication. It allows teachers to compare between classrooms and year groups and potentially fosters collaboration between teachers and specialist practitioners who focus on communication such as speech and language therapists. Further work could link the observation tool into an intervention program co-constructed with teachers.

\section{SCHOLARONE ${ }^{\text {m }}$ \\ Manuscripts}




\begin{abstract}
Background

The nature of "Teacher talk" is likely to have a considerable bearing on the child's learning but measuring the communication environment in the classroom can present challenges. One tool which does this is the Communication Supporting Classroom Observation Tool (CSCOT). Initial use suggested that it was valid and reliably used by specialists (psychologists and speech and language therapists) and SENCOs. A key question is whether it can be used routinely by classroom teachers and whether results coincide with those in earlier studies.
\end{abstract}

\title{
Method
}

CSCOT observations were carried out by teachers in 33 schools (32 Reception classrooms, 25 in Year 1 and 25 in Year 2) in two local authorities in the North East of England and teachers were asked afterwards to reflect on their experiences using the tool.

\section{Results}

Scores were in line with those in earlier studies and were consistently higher on all dimensions for reception compared to Year 2, but there was no difference between other year groups. Results were mostly consistent with the original studies. Language learning environment was higher relative to both language learning opportunities and interactions across all years (which again did not differ). There was a moderate interaction between language learning environment where scores were significantly higher in the Reception group and lower in the Year 2 group. Teachers supported the use of the CSCOT in their feedback, suggesting that CSCOT was easy to use and useful in informing practice. 


\section{Conclusions}

The CSCOT clearly has utility as a starting point in auditing classroom communication. It allows teachers to compare between classrooms and year groups and potentially fosters collaboration between teachers and specialist practitioners who focus on communication such as speech and language therapists. Further work could link the observation tool into an intervention program co-constructed with teachers. 


\section{Background}

The development of oral language skills in early childhood is central to the child's capacity to succeed in the classroom and the playground (Ashman \& Conway, 2017; Mashburn et al., 2008; Justice, 2004) and in specific academic tasks such as the acquisition of subject-specific vocabulary (Nagy \& Townsend, 2012) and both reading and writing (Cabel et al., 2015; Duncan et al., 2007; Whorrall \& Cabel, 2016). Yet, the amount and type of language and emergent literacy activities vary considerably in preschool and early years classrooms, potentially leading to very different preschool communication experiences (Connor et al., 2006). For example, Wright and Neuman (2014) found evidence for preschool teachers inconsistently explaining word meanings when teaching words, or teaching words in an intentional, pragmatic and context-driven manner. Further, these differences were sensitive to social demographics. As such, it is useful for teachers to be aware of their own communication skills and the way they can foster the communication skills of their pupils.

There are three key elements to the classroom language environment. Firstly, language learning environments (LLE) give children access to further language development and provides numerous opportunities for children to communicate with their classroom peers and adults (Justice, 2004). Print-rich classroom environments are likely to contain reading and writing areas, student displays of work and topic display areas containing physical materials and props which give children the opportunity to comment and express ideas with others (Dowhower \& Beagle, 1998; Justice, 2004). Secondly, creating language learning opportunities (LLO) for children enhances their oral language and 
significantly impacts on language learning. Examples of this are adult-led story book engagement, structured interactions with both peers and adults in the classroom, and smaller but inclusive group work (Brigman \& Webb, 2003; Chapman, 2000; Coyne et al., 2009; Justice et al., 2011; Mashburn et al., 2009; Turnbull et al., 2009). Finally, engaging children in high quality language learning interactions (LLI) with adults in the classroom is important for oral language development. For example, repeated and extended interactive instruction by teachers during storybook reading leads to significant gains in vocabulary and both receptive and expressive language more generally (Wasik \& Bond, 2001; Coyne et al., 2009). Although these skills are important in their own right, it is also important to know how these play out across year groups and also how they interrelate with one another and the impact that this would have on teaching practice (Long, Sanetti, Collier-Meek, Gallucci, Altschaefl \& Kratochwill 2016).The concern would be that LLE might be relatively high but that this would not affect the levels of LLO or LLI implemented, with schools effectively using equipment as a proxy for teacher led activity. Another concern relates to the tension between the language learning needs of children within the classroom, and having these fit alongside the requirements of the English classroom curriculum. In England the 'Statutory Framework for the Early Years Foundation Stage' (SFEYFS; Department of Education, 2017) and the English National Curriculum for Key Stages 1 and 2 (Department of Education, 2013) both emphasise the importance of oral language and literacy, and are considered key areas of learning and 'an essential foundation for success in all subjects' (English National Curriculum, 2013; p.10). The SFEYFS lists communication and language capabilities as supportive of literacy, one of the 'prime areas' of learning, and the English National Curriculum 
highlights achievement in speaking and listening skills as an important aim for the English Subject in Key Stages 1 and 2 (DfE, 2013). However, this needs to be considered against a background of educational funding in the UK which is being increasingly devolved to schools (ICAN \& RCSLT, 2018), allowing schools to make their own choices about the programs they adopt driven by pressure to achieve well in formalised assessments such as SATs. The concern is that a tension may arise as teachers attempt to reconcile the communication needs of the child and the demands of the curriculum.

\section{Classroom observational measures}

As these areas may be insufficient or inconsistent across classrooms, how we measure these aspects of the environment is key to improving them. A number of observational measures have focused on examining teachers' language promoting practices. For example, The Classroom Assessment Scoring System (CLASS; Pianta et al., 2007), and Early Childhood Environment Rating Scale - Revised (ECERS-R; Harms et al., 2004; see Law et al. 2004) are well evidenced measures which have been used to examine classroom quality (e.g. LoCasale-Crouch et al., 2007), but the scope of what they measure are more restricted. The CLASS only examines the social and emotional climate and instructional supports for learning in a classroom, while the ECERS-R focuses on the quality of provision for language and literacy development for nursery and preschool children in classroom communication. Another measure is the ICAN Primary Talk Programme (ICANPTP; I CAN, 2007) which specifically focuses on KS1 and KS2 language and communication levels and includes both a related training programme (Primary Talk Supporting Communication) and a classroom observation tool (e.g. 
Stackhouse et al., 2009, Leyden et al., 2011, ICAN, 2016). Although considered valuable by practitioners (Stackhouse et al., 2009; Leyden et al., 2011, ICAN, 2016), there has been little rigorous research on its efficacy or validity. It also focuses upon the evaluation of the effectiveness of the programme and training, rather than being a comprehensive observation tool for language learning practices. The observations focus on single children rather than whole classrooms, and so some sensitivity of the tool to the actual changes in language learning as a result of the training may be lost. The other issue which is of paramount importance is who actually carries out these observations and how this then does or does not feed into practice changes. In many cases such as the ECERS-R it is commonly an "outsider" - i.e. a researcher comes in to make the relevant judgements. Although teachers can be called upon to carry it out, there is an assumption that such professionals are both readily available, that they see it as their role and that schools are ready to engage with them on such an enterprise. But, of course, if the aim is not just for measurement, but response to that measurement within the school, the classroom teacher is, we would suggest, central to the process and should be the one carrying out the observations. Of course, they cannot readily observe themselves directly and this calls for a school wide approach drawing on communities of practice to bring about change (Schlager \& Fusco (2003).

One tool which has been created to include these three elements is the Communication Supporting Classrooms Observation Tool (CSCOT) (Dockrell et al., 2012; 2015). These papers report the development of the CSCOT measure and the results of a feasibility study carried out over 101 classrooms in 39 schools across 10 local authorities in 
England. The results suggested that the CSCOT discriminated well between different age groups within the sample (Reception (4-5 years), Year 1 (5-6 years) and Year 2 (6-7 years)) and between different schools. In addition, significant differences were found across the three dimensions of the CSCOT measure Results suggest that the tool can be reliably applied across different schools and communication domains, and can be used to audit current practice capturing a classroom's communication strengths and weaknesses. However, the initial Dockrell et al. (2012) study examined CSCOT observations made by practitioners who specialized in language development (e.g. speech and language therapists, psychologists etc.) and by SENCOs rather than the classroom teachers themselves. The key to the deployment of such measures is that they must be functionally useful to the teacher in the classroom, but recording teachers' experiences was not part of the initial study. Concern has been raised about how little attention teachers pay to empirical evidence when making decisions in the classroom (Dagenais et al., 2012). A systematic approach to implementation would provide teachers with understanding of the evidence supporting the measure as well as the knowledge and means to carry it out (Michie et al., 2011). Barriers to and enablers of research implementation, and consequent change in practice, are dependent on the context in which the practitioners are working (e.g. Squires et al., 2019). An external professional's implementation strategy would take account of context at different levels in the school so that increased capability and opportunity to use the measure would increase motivation to routinely adopt the new behaviours indicated by the measure. Key to this normalisation of new practice is engagement of the class teachers in the process. 
A recent study suggested that SENCOs were able to utilize the CSCOT to assess classrooms, but this was for the purpose of testing professional alignment in the management of children with Speech, Language and Communication Needs (SLCN) (Vivash, Dockrell and Lee, 2018). This paper addresses the role of educational psychologists (EPs) in relation to SLCN suggesting that this role has been largely peripheral to date but could be enhanced through classroom observation. Drawing on 12 observations in Key Stage 1 classrooms (KS1; the first two years of primary schooling including children aged 5-7 years old), these were followed by interviews with 40 staff. The authors concluded that there was inconsistency of practice around strategies and approaches for supporting SLCN, especially with the nature of adult talk but there were discrepancies between the way that EPs and teachers viewed the issues. In the present paper, we focus on its replicability relative to the earlier studies and test teacher satisfaction with the tool, thus extending the earlier analysis by involving classroom teachers in the observations and then asked those teachers to reflect on its utility, acceptability and feasibility.

The present study therefore had four aims:

1. To establish whether the CSCOT can be routinely used by classroom teachers;

2. To compare the differences in language learning environments, opportunities and interactions between classrooms in the first three years of school (Reception, Year One and Year Two) via CSCOT Observations carried out by educational staff;

3. To identify classroom teachers' views on using the CSCOT tool; and 
4. To consider further developments for the CSCOT.

\section{Method \\ Design}

The study adopted a mixed design. The quantitative element included a $3 \times 3$ repeated measures ANOVA design across dimensions with year group as a between group factor. The year groups comprised of Reception, Year 1 and Year 2, and the language learning dimensions included Environment, Opportunities and Interactions. The dependent variable was the mean proportion score for each language learning dimension. The CSCOT was completed by teaching staff. The qualitative component involved teachers who completed the CSCOT giving their feedback on their experience of the measure.

\section{Participants}

Schools were recruited from two local authorities in the North East of England as part of the Transforming Tees project, a local school improvement initiative. A total of 43 schools attended a 1 day training workshop delivered local to the schools within their local authority. In the training sessions the importance of oral language for literacy and its relationship to school outcomes was explained, followed by the provenance, detail and early findings of the CSCOT and the aims of the present study. As part of the workshop, teachers were asked to reflect in small groups about the recognition of the importance of the behaviours outlined in the CSCOT for their school. Of the schools originally recruited only eight did not participate further. Therefore, 35 schools participated in the observation, but following data cleaning a total of 33 schools were included. One school 
was excluded because it was a special needs schools and a second because it only provided data pooled across years. A total of 82 classrooms took part (Reception, $n=32$; Year 1, $\mathrm{n}=25$; Year 2, $\mathrm{n}=25$ ) with a total of 2,369 children (Reception: 1,005; Year 1: 680; Year 2: 684) aged between 4-7 years old. Forty teachers were involved, with 25 completing multiple observations ( 2 observations, $n=5 ; 3$ observations, $n=17 ; 4$ observations, $n=3$ ). Seven of these observations had more than one teacher present, as practitioners in one local authority wanted to do the observations together. The schools involved in the study had an average 51\% Free School Meal Rate and an average Good Level of Development (a measure of attainment at the end of the Early Years Foundation Stage) of 66.6\%, which is slightly below the national (69.3\%) and North East of England averages (68.4\%) (GLD, 2016).

Feedback: At the end of the CSCOT observations, the 36 teachers who took part in the CSCOT observations from the 33 schools were given a questionnaire with both open and closed questions eliciting feedback on the process. Three teachers from one school and one teacher from another school elected to take part in a further face-to-face semistructured feedback session about their involvement in the project. Thus, a total of 23 teachers from 21 schools provided feedback.

\section{Materials}

Communication Supporting Classrooms Observation Tool 
The CSCOT is a booklet comprising three observational subcategories: language learning environment (LLE); language learning opportunities (LLO); and language learning interactions (LLI). These are further defined in the 2015 paper as:

- Language Learning Environment, the physical environment and learning context;

- Language Learning Opportunities, the structured opportunities that are present in the setting to support language development; and

- Language Learning Interactions, the ways in which adults in the setting talk with children.

The tool includes guidance on what to observe for each item, with examples of practice and an explanation of the item. To account for the different numbers of items across the three dimensions, proportion scores were created (Dockrell et al. 2015). Proportion scores were derived by dividing the actual number of observations by the total number of possible observations. These proportion scores range from 0 (not recorded) to 1 (maximum possible numbers of occurrences), where items were rated on the basis of a maximum of five occurrences. Both electronic and paper versions of the CSCOT were provided. The tool is available from the Communication Trust (http://www.thecommunicationtrust.org.uk/resources/resources/resources-forpractitioners/communication-supporting-classroom-observation-tool/).

\section{Procedure}

Observations were completed during the spring term (Between March and April 2017). Teachers completed one-hour observations of a morning classroom teaching session for each year group (potentially totaling three observations in each school). In one example, 
teachers from three associated schools observed each other's classrooms. They then scored each of the language learning areas (environment, opportunities and interactions) from the observation of a lesson, and the completed observations were returned to the research team for analysis. The feedback questionnaires (see Appendix 1) were sent to the teachers electronically and both the single-teacher and group feedback sessions were carried out on the premises of two of the participating schools.

\section{Ethical considerations}

The study was approved by the Newcastle University Ethics Committee. Each head teacher gave consent for their teachers to be involved in the project and class teachers could opt out of the project. In health parlance the study was considered to be service development rather than research because the activities proposed were an enhanced version of routine practice

\section{Results}

\section{The CSCOT observations}

Proportion scores across the three year groups (Reception, Year One and Year Two) and for each CSCOT dimension are provided in Table 1 and Table 2 respectively. Performance score differed significantly by language learning dimension $\mathrm{F}(1.74$, $119.74)=92.790, p<.001, \eta^{2}=.57$. LLE scores were found to be significantly higher compared to both LLO and LLI (both $p<.001$ ). However, there was no significant difference in overall performance between LLO and LLI $(p=.82)$. Furthermore as shown in Table 1, Reception teachers observed significantly better performance on the CSCOT 
than Year 2 teachers $(p=.012)$, but not than Year 1 teachers $(p=.054)$. Year 1 and Year 2 teachers did not differ on any of the CSCOT dimensions $(p=1.00)$.

Table 1 Mean (SD) Proportion Scores for Year Group and Dimension

\begin{tabular}{lllll}
\hline & Reception & Year 1 & Year 2 & ALL \\
\hline Language Learning & $.89(.08)$ & $.71(.17)$ & $.63(.17)$ & $.74(.02)$ \\
Environment (LLE) & & & & \\
Language Learning & $.53(.18)$ & $.45(.20)$ & $.45(.21)$ & $.47(.02)$ \\
Opportunities (LLO) & & & & \\
Language Learning & $.47(.19)$ & $.45(.20)$ & $.45(.17)$ & $.46(.02)$ \\
Interactions (LLI) & & & & \\
ALL & .63 & .53 & .51 & \\
\hline
\end{tabular}

Table 2. Mean (SE) Difference in Proportion Scores between Dimension

\begin{tabular}{lc}
\hline \multicolumn{1}{c}{ Group } & Mean (SE) \\
\hline LLE versus LLO & $.27(.03)$ \\
LLE versus LLI & $.29(.03)$ \\
LLO versus LLI & $.02(.02)$
\end{tabular}

Finally, as shown in Table 3, there was a significant, albeit modest, interaction between year and dimension, $\mathrm{F}(3.47,119.74)=4.597, \mathrm{p}=.003, \eta^{2}=.12$. This indicates that language dimension performance differed according to year group. LLE scores were the highest across the year groups, with Reception scoring the highest, and Year 2 scoring the lowest (Reception, $\mathrm{M}=.89, \mathrm{SD}=.08$; Year $1, \mathrm{M}=.70, \mathrm{SD}=.17$; Year $2, \mathrm{M}=.63, \mathrm{SD}$ 
$=.17)$. However, there were no significant differences across the three year groups for LLO and LLI scores. LLO and LLI scores were also higher in Reception (Reception LLO, $\mathrm{M}=.53, \mathrm{SD}=.18 ;$ Reception LLI, $\mathrm{M}=.47, \mathrm{SD}=.18)$ than Year $1($ Year $1 \mathrm{LLO}$, $\mathrm{M}=.44, \mathrm{SD}=.20 ;$ Year $1 \mathrm{LLI}, \mathrm{M}=.45, \mathrm{SD}=.20)$ and Year $2($ Year $2 \mathrm{LLO}, \mathrm{M}=.45$, $\mathrm{SD}=.21 ;$ Year $2 \mathrm{LLI}, \mathrm{M}=.45, \mathrm{SD}=.17)$. The non-significant results previously outlined are due to a similarity between Year 1 and Year 2 LLO and LLI scores.

Table 3. Mean (SE) Difference in Proportion Scores between Year Groups

\begin{tabular}{lc}
\hline \multicolumn{1}{c}{ Group } & Mean (SE) \\
\hline Reception versus Year 1 & $.10(.03)$ \\
Reception versus Year 2 & $.12(.03)$ \\
Year 1 versus Year 2 & $.02(.02)$ \\
\hline
\end{tabular}

The results were comparable to those between reception and year 2 identified in Dockrell et al. (2015), but the differences between reception and year 1 were not statistically different from one another and year 1 and year 2 were rather 'flatter' in the present study than they were in the original study.

[Figure 1 about here]

\section{Teacher feedback on the use of the CSCOT}

The teachers were asked to reflect on their experiences of using the CSCOT and then fill out a simple post observation questionnaire. The questionnaire was designed specifically to relate to the CSCOT (i.e. it was developed to allow the research team to access 
feedback from teachers in a consistent manner, and items were seen to be independently important rather than a cohesive whole with a single score). Questions in the single and group feedback sessions were the same as the questionnaire, but provided in a semistructured format with the aim to allow teachers to provide deeper discussions surrounding questions or to add anything outside of the questions posed. This was offered to all schools, but only two schools accepted. Largely for reasons of time the three teachers in the group session provided feedback together in a single session. Although the latter arrangement allowed more interaction between teachers, what they actually said was in line with what was said by teachers answering with the standard questionnaire format, and so this feedback was integrated with the questionnaire responses. Some examples of the feedback are provided below.

\section{Logistics}

An open question of 'How did you find arranging and completing the observations for this project?' was used to elicit responses. Some examples such as ease of logistics to arrange observations, having adequate time to complete them, teachers/teaching staff being comfortable being observed, understanding how to mark items were included as a guide. $30 \%$ of teachers mentioned the ease of completing the CSCOT, and all said it was simple enough to complete and its guidance clear. $26 \%$ of teachers mentioned the comfort of those observed, with one stating it made the observed feel uncomfortable, and another stating it made teachers initially wary. However, the other four reported that teachers were happy to be observed. One issue which seemed evident was that almost all teachers $(74 \%)$ reported difficulties with finding time/ completing the full hour of the 
CSCOT. This was mostly due to their workloads and/ or finding cover for lessons. This indicates that considerable care needs to be taken when introducing CSCOT into schools to ensure that sufficient support is available for those involved.

\title{
Utility
}

When asked if they have been using or plan to use any new programmes to promote oral language and communication skills for all children in their classrooms since the CSCOT observations, $48 \%$ of teachers said yes. Two thirds of respondents also stated that they felt more confident discussing children with speech, language and communication needs with SLTs since completing the CSCOT observations. Moreover, $54 \%$ of the responders agreed that teachers and teaching staff require further training on oral language and communication skills and needs in their school.

Items

Teachers stated that LLO and LLI were the most useful language learning dimensions to observe ( $46 \%$ each; LLE $=29 \%$, some practitioners selected more than one). Teachers appeared to select LLO because they found it clearly connected to the standard practice encouraged within a classroom (due to its relationship to language learning):

\author{
"Children learn from others and modelling, rephrasing and extending \\ children's utterances allows them to hear correct language. Providing \\ gestures reinforces children's understanding and using new vocabulary
}


in context and with props or pictures supports their use of the new vocabulary."

For teachers who selected LLI, they considered it the most important as it allowed them to understand the child's language level and especially its relationship to prereading skills and planning for the next developmental stage:

\begin{abstract}
"It is important for teachers and teaching staff to see and hear the range of interactions that occur in the EYFS classroom. How experienced and skilled staff can challenge and develop the children's thinking, develop their use of language and introduce new language to children's talk at this early stage of their development. Speaking and Listening is vital in their learning of Reading."
\end{abstract}

\begin{abstract}
When asked if there were any items which teachers felt were difficult or impractical to implement, issues were mostly raised in Year 1 and Year 2 classrooms. Concerns were explicitly expressed by $30 \%$ of respondents, that play in general and language learning opportunities and interactions in particular were not as relevant concerns for children in KS1 as they were for those in reception.
\end{abstract}

\begin{abstract}
"Labelling and turn-taking in Y1 and Y2: This may be due to the activities they do, as the children are already confident and capable and past this stage; so may not be as appropriate to implement in these years. Teachers
\end{abstract}




\begin{abstract}
still do it for children who were still struggling or as a reminder, but the
teacher probably doesn't need to re-iterate this for older children as they

are demonstrating these skills adequately. But, constantly done in

reception to develop those skills."
\end{abstract}

\begin{abstract}
However, in the original guidance it states "It is not expected that all items will appear on all observations." Furthermore, it is interesting to note that this judgement runs contrary to the literature which suggests that all these domains are essential as the children progress, especially for children from more socially disadvantaged areas.
\end{abstract}

\title{
Differences between year groups
}

Practitioners were asked about any differences that they noticed when observing the language learning areas. From their comments, it was apparent that there was a separation between Reception and Years 1 and 2 in some prominent ways.

The first difference was the discrepancy in the language environment in Reception compared to KS1 classrooms. $65 \%$ of practitioners noted that language materials/ areas were more likely to be present and of higher quality in Reception and that these areas encouraged more child-initiated language and opportunities than they do in Years 1 and 2.

\author{
"Lots more environment(al) language in the Early Years. Also lots more \\ interactions and opportunities for language in the Early Years due to the \\ way it is set up."
}

In relation to this, the second key difference was that $48 \%$ of teachers noted there was less opportunity for the language learning practices, as Year 1 and Year 2 classrooms are 
more formalised (for reasons such as SATs) and the opportunity and interaction elements of the CSCOT to were expected to be observed or present as children progress through the school.

'Year 1 and Year 2 have these differences because they're more formal, and they have to be for phonics tests, SATs etc, so I don't think there could be specific areas for Year 1 and Year 2 children.'

Where they did occur they were often brought out for a very specific purpose and in one case the placement of communication materials and literacy areas were completely separate from and 'not expected' to be in the classroom. They were located in a corridor for use at specific times, and resources/ areas were also shared with other classes.

\title{
Proposed teacher changes to the classroom
}

A final question examined examined proposed changes to the teachers' own classroom after they completed the CSCOT observations.

\author{
In regards to the language learning areas, the biggest focus was LLE, with $61 \%$ of \\ teachers proposing changing the language learning environment. This included changing \\ the displays to be more interactive and engaging in classrooms and implementing more \\ 'communication friendly' spaces around schools and in classes. 39\% of teachers had \\ plans to change LLO areas, and involved getting children talking more to peers and \\ adults, which seemed to be by changing the nature of some of the classroom tasks or \\ play. How this would happen was not clearly outlined by any of the responders. Finally, \\ only $22 \%$ proposed changes for LLI, some did outline more specific changes which
}


involved training staff about different interactive techniques, making time for teachers to interact with children and using specific tasks to engage in more interactive discourse between children and adults.

\begin{abstract}
When explicitly mentioning year groups ( 8 teachers) plans for change were mostly focused on Reception (all 8), and 3 of these teachers planned to make changes for year 1 (and within this 1 teacher stated it would be for children with delayed language only), whilst only 2 had plans to implement across all year groups.
\end{abstract}

Teachers also proposed changes outside the CSCOT areas and items. In particular, one practitioner focused on changing staff's age-related expectations for language and communication development, and another was proposing to get staff to share good practice within teams. Five teachers indicated that they were planning to examine the nature of their lessons due to CSCOT and aimed to see which topics or type of lesson were good for language learning, and some wanted to generalise or adapt this to other lessons and year groups.

\title{
Discussion
}

This is the one of the first studies to use the CSCOT with classroom teachers. Clearly staff engaged with the process suggesting that the CSCOT can be a useful tool in fostering oral language skills in the classroom (Ashman \& Conway, 2017; Connor et al., 2006). When comparing observation scores to the predominantly specialist observers in Dockrell et al. (2012/2015), there is a similarly clear distinction between Reception and 
Year 2. Year 2 children's observation scores are comparable but lower overall. This is especially relevant for factors in the language learning environment but is less sensitive to interaction and communication opportunities. Whereas Dockrell et al. found a significant difference in performance between all three dimensions, the present study did not. It is important to emphasise that the CSCOT was never intended to test the relative difference between the three subdomains. We received a strong message from teachers' feedback that, from their perspective, the communication opportunities and interactions were less salient as children progressed. This is concerning because it does not reflect what is understood from the literature, especially with children from more socially disadvantaged families. It is important to highlight that although the schools in this study had relatively high free school meal rates, they had an average "good level of development" (GLD) suggesting that the results reported here may be indicative of those across the country.

\section{Further directions of CSCOT and practice}

Many teachers found the CSCOT functionally useful because it highlighted their current practice and drew attention to aspects of interaction which they had not previously considered. The findings also suggest that the CSCOT effectively provides a forum for discussion about classroom practice - a means of communicating about communication, while at the same time providing the space to do so. We were asked by some teachers whether there were specific activities which would allow teachers to address perceived gaps identified by the CSCOT. There is no "intervention" derived from the CSCOT but there clearly could be, and so will be worked on by the research team in the near future. 
It is important to acknowledge that the CSCOT is an observational scale and not a "to do" list for teachers to complete every item in the tool. This means there may not be a direct relationship between what is observed and the teachers' response to those observations. The solution in our view would be to work closely with teachers to co-construct evidence informed interventions for aspects of the CSCOT which would fit with practice in the school, test the implementation by looking at the performance of the children and to share good practice where it is identified.

Schools are increasingly driven by attainment targets and this shapes how much teachers prioritise communication in the classroom over specific curriculum activities. Effective communication is key for both peer to peer and peer to adult interaction, collaborative learning in school and ultimately the workplace where communication skills are highly valued. Given the concerns that have been raised about teachers use of evidence (Dagenais et al. 2012), our suggestion is that instruments such as the CSCOT have the potential to feed into the training of teachers and be employed to start a conversation between teachers and external professionals about evidence. It will therefore act effectively as a middle ground between the evidence gained from a teacher's experiential learning and the type of external evidence found in peer reviewed publications of the type used to generate the original items in the CSCOT.

\footnotetext{
It is also important to consider the variations between the year groups. There is a change in environmental factors across the year groups with year 2 children having far fewer communication relevant resources than reception children. While the opportunities and
} 
the interactions are also higher in reception than the other two years, there are no differences between the two later years. Both of these findings reflect what some teachers told us, namely that communication is less of a focus as children move out of the reception class. This is clearly a concern because children are being given less opportunities to interact with their peers and other adults. It could be argued that teaching happens in the classroom and communicating happens elsewhere - in the playground, at home, on-line etc. - but the key issue here is that experienced adults are not able to structure these interactions in a way that they are in the classroom. This raises fundamental questions about the role of the teacher in the classroom and the relationship between functional skills and curricula. Thus there is a need to use measures such as the CSCOT with teachers, and work with them to find solutions to the issues raised by the scale. An example of such a program is Supporting Spoken Language in the Classroom knowledge exchange program (SSLiC https://www.ucl.ac.uk/ioe/departmentscentres/centres/centre-for-inclusive-education/supporting-spoken-language-in-theclassroom) which supports professionals through a process of auditing pupils existing language-use in a school using the CSCOT making changes across the school and within classrooms. SSLIC is aimed at all school professionals working in Reception and KS1 and supports the development of a systematic whole school approach to language awareness, use and support, developing classroom teacher's skills in the identification of issues associated with language-use in the classroom.

The important point here is that the CSCOT is a self-help tool. It is clear from the data presented in this study that both teachers (consistent with clinicians) have observed considerable differences within classrooms in terms of how much they actively promote 
children's communication skills. As such, the audit capacities of the CSCOT have been shown to be a useful starting point for these discussions. Although speech and language therapists can usefully bring their expertise to improving promotion of children's communication skills in the classroom and help with the interpretation of the CSCOT, they are a scarce resource, so the findings presented here suggest that adoption of the CSCOT could allow schools to improve their own communication environments. Yet, in practice, there are often advantages in having the support of an outside professional feeding into communities of practice within and across schools (Schlager. \& Fusco 2003; Long et al. 2016). Simply getting started was an issue for many with $74 \%$ of teachers registering a challenge to prioritise an hour to complete the CSCOT as was the need for training (e.g. the one-day training provided in this study). Our conclusion would be that support from an outside professional such as a speech and language therapist should be a prerequisite to introducing the process and ongoing support a distinct advantage when it comes to interpreting the results of the observations. Many SLT services already include the CSCOT as part of their 'offer' to schools and clearly there is also support available from educational psychologists (Vivash et al. 2018). That said, our view is that teachers need to be central to this whole process. They are the ones to identify the need to make such observations and ultimately the ones who need to change their practice and their environments.

\footnotetext{
Our data suggest that the content of the CSCOT helped teachers understand further training needs, as well as helped improve their understanding of good quality language and communication programmes. But one of the key issues is the assumption that many
} 
of these communication issues are perceived as less important as the curriculum becomes more formalized in Year 1 and Year 2 classrooms (due to SATs). By contrast, the language learning environment was picked up and prioritised by teachers. The evidence suggests that this may be easier to change but is ultimately less important than what opportunities and interactions teachers actually provide for the children. As such, we would strongly disagree with the prioritization of the material environment at the expense of communication skills (captured in LLO and LLI) which play such a central role in a child's well-being and prospects.

Where communication has been prioritised by senior staff, change in practice needs to be initiated from within the school or group of schools, academy trusts etc. However, it is likely to need support and additional expertise, with external professionals, such as speech and language therapists, playing an important role in enhancing objectivity and informing or leading the process of change. For the CSCOT to be optimally effective, with sustained adoption into classrooms of communication behaviours in all three domains (LLE, LLO and LLI), external professionals are advised to adopt a robust implementation strategy (Michie et al., 2014). This would demonstrate an appreciation of both external and internal pressures on school leaders and class teachers, acknowledging the difficult and sometimes uncertain context in which they work. It would include senior school leaders, such as head teachers and SENCOs in the process ensuring implementation is supported throughout the organisation and teachers are provided with adequate opportunity to carry out the CSCOT. It is evident from this study that the process of gaining head teachers' consent for their staff to participate did not guarantee 
protected time for teachers to implement the CSCOT. Comments from teachers indicated that although the CSCOT helped them to identify good practice, it also highlighted gaps in their capability (knowledge and skills) and opportunity (time and resources) to promote communication skills in the classroom. Training, for school leaders and class teachers, would incorporate understanding of the underpinning evidence into the knowledge of how to carry out the measure, leading to increased capability and motivation to use the CSCOT. The desired outcome of this would be sustained implementation of best practice through the normalisation of identified communication behaviours into classroom routines (May et al., 2007; Michie et al., 2011).

\section{Study limitations}

While the feedback reported here can be construed as "indicative", a more comprehensive study of teacher feedback would be warranted, perhaps with focus groups discussing the findings of a survey of involved participants and explicitly looking for the experiences of different teachers sampled purposive for age, qualification, experience etc. For example we were not able to explore in any depth why teachers appear to reduce the emphasis on opportunities and interactions beyond the fact that they saw the later classrooms as pivoting towards the curriculum rather than oral language development. Our conclusion is that it would also be worth exploring further the response in different types of schools - those that are privately funded and grant maintained, academies etc., with those containing more or less socially disadvantaged pupils, or those from rural and inner-city environments (an approach started in Dockrell 2012/2015). But, again for this to work this would require specific sampling of schools across a bigger area than was included in the present study. 
In terms of the characteristics of the teachers involved in the study we do know that they were early years teachers. We do not know how long they have been in post or qualified, the nature of their own training, their own attitudes to schooling, child development etc. Exploring such variables could be interesting although not without complications in terms of engaging the teachers in this work. It is also not clear what one would hypothesise here. Presumably that younger teachers with all the most recent evidence at their disposal would focus more on their children's communication skills. That said, we have discussed this in a follow up to this project (not included in this study) and the view seemed to be that it was the experience - in terms of age group taught and of children with special educational needs more generally, which made a difference rather than the number of years as a teacher per se.

Because our task was to engage teachers in the process, we did not formally test interrater or intra-rater reliability. Our concern was to avoid the perception of "checking up" on the teachers in the manner adopted by OFSTED. So, our approach was relatively light touch at this stage. This was tested in the original paper and was found to be sound using external observers, thus for Language Learning Environment it was 83\%, Language Learning Opportunities it was $71 \%$, and for Language Learning Interactions, it was at least $84 \%$. But it is important to stress that, even if the tool is reliable, it is not necessarily valid if the construct is a problem - hence the evidence informed generation of the items. This would be a direction of travel for future research. 


\section{Directions for future research}

Clearly the CSCOT has utility for the teachers involved in this study. It is useful as an audit tool and as a method of highlighting key aspects of the communication environment at a school level. It has the potential to raise teachers' awareness of the issues concerned and opens up a discussion about how to best address these needs, creating a context allowing SLTs and teachers to work more collaboratively. Although we have addressed two approaches to validity here (replication of the initial study and teacher feedback), it could be argued that the next stage would be to compare directly the observations of teachers and external observers to check for both interrater reliability and validity, and then discussing the differences between the different groups concerned. Another area of potential investigation is the impact that different patterns between the subscales of the CSCOT played out against pedagogical practice. If LLE is relatively high and LLO/LLI relatively low or vice versa what impact is this likely have in the classroom in terms of child performance?

Furthermore, the arguments for the adoption of such measures might be stronger from an educational perspective if the findings from the CSCOT could be shown to be associated with the results of the Early Years Foundation Stage Profile. One might assume that better communication environments would lead to better performance on the Communication Language and Literacy scale of the EYFS, for example. Ultimately the most convincing research evidence would demonstrate that the introduction of the CSCOT and associated practice changes could reliably affect not just the teacher-child interaction but the outcomes for the children concerned. 
One of the strengths of the study was that although the schools involved had a relatively high Free School Meal rate (51\%) they had an average GLD. This helps the generalization of the results to the extent that we can generalise to schools performing within the average range, but the problem of communication in the classroom may be particularly relevant for schools where there are high levels of social disadvantage and with lower levels of GLD. It might be anticipated that such schools would have lower scores overall on the CSCOT reflecting the likely lower average language performance of the children concerned and would thus present a rather different picture and perhaps offering greater opportunities for change. An alternative interpretation might be that lower GLD schools commonly receive more resources (for example in England through the Pupil Premium mechanism) and, therefore, might well be anticipated to put more resources into developing their pupils' communication skills and so may have higher rather than lower scores in the CSCOT. Indeed, it may be possible that this is reflected to some extent in our sample with high free school meal rates but average GLD performance. Thus, a further study could potentially explore the differences in classroom environments of schools with different social characteristics.

Finally, it is important to acknowledge that the CSCOT is only one amongst a number of observational schedules (Pianta et al., 2007; Harms et al., 2004; LoCasale-Crouch et al., 2007) and there has been no direct comparison of the utility of these measures and the extent to which they do and do not overlap. They clearly measure different phenomena although communication is common to them all to a greater of lesser extent. 


\section{Conclusions}

The CSCOT clearly has utility as a starting point in auditing classroom communication. It allows teachers to compare between classrooms and year groups and between school clusters. It may potentially help in fostering collaboration between teachers and specialist practitioners such as speech and language therapists. Further work could tie the observation tool into an intervention program targeted at specific aspects of communication identified in the tool. 


\section{Declaration of Conflicting Interests}

Both Law and Dockrell were involved in the original development of the CSCOT but have no financial involvement in its dissemination which is managed by The Communication Trust.

\section{Funding}

The schools have been partially supported for their involvement in this study by the North East Literacy Campaign funded by the Education Endowment Foundation and the Northern Rock Foundation. The specific project for which data are provided in this paper was funded by the ESRC Impact Acceleration Fund administered by Newcastle University. 


\section{References}

Ashman AF, and Conway RN (2017) Using cognitive methods in the classroom. UK: Routledge.

Brigman GA, and Webb LD (2003) Ready to learn: Teaching kindergarten students school success skills. The Journal of Educational Research, 96(5): 286-292.

Cabell SQ, Justice LM, McGinty AS, DeCoster J, and Forston LD (2015) Teacherchild conversations in preschool classrooms: Contributions to children's vocabulary development. Early Childhood Research Quarterly, 30: 80-92.

Chapman JW, Tunmer WE, and Prochnow, JE (2000) Early reading-related skills and performance, reading self-concept, and the development of academic selfconcept: A longitudinal study. Journal of educational psychology, 92(4): 703708.

Connor CM, and Craig HK (2006) African American preschoolers' language, emergent literacy skills, and use of African American English: A complex relation. Journal of Speech, Language, and Hearing Research, 49(4): 771-792.

Coyne MD, McCoach DB, Loftus S, Zipoli R Jr, and Kapp S (2009) Direct vocabulary instruction in kindergarten: Teaching for breadth versus depth. The Elementary School Journal, 110(1): 1-18.

Dagenais C, Lysenko L, Abrami PC, Bernard RM, Ramde J, and Janosz M (2012) Evidence \& Policy: A Journal of Research, Debate and Practice, 8(25): 285-309. DOI: https://doi.org/10.1332/174426412X654031

Department for Education (2013) English National Curriculum. London: UK Government Printing Office. 
Department for Education (2017) Statutory Framework for the Early Years Foundation Stage. London: UK Government Printing Office.

Dockrell JE, Bakopoulou I, Law J, Spencer S, and Lindsay G (2012) Developing a communication supporting classrooms observation tool. London: UK Department of Education Printing Office.

Dockrell JE, Bakopoulou I, Law J, Spencer S, and Lindsay G (2015) Capturing communication supporting classrooms: The development of a tool and feasibility study. Child Language Teaching and Therapy, 31(3): 271-286.

Dowhower SL, and Beagle KG (1998) The print environment in kindergartens: A study of conventional and holistic teachers and their classrooms in three settings. Literacy Research and Instruction, 37(3): 161-190.

Duncan GJ, Dowsett CJ, Claessens A, Magnuson K, Huston AC, Klebanov P, ... and Sexton H (2007) School readiness and later achievement. Developmental psychology, 43(6): 1428-1464.

Harms T, Clifford RM, and Cryer D (2004) Early Childhood Environment Rating Scale (ECERS-R). US: Teachers College Press.

I CAN (2007) Primary Talk. [Training and accreditation package]. London: I CAN.

I CAN (2016) Evaluation of Primary Talk Supportive Level Training. London: ICAN. Retrieved from http://icancharity.org.uk/sites/licensing.ican.org.uk/files/PT-Supp$\underline{\text { Training-Evaluation-project-report.pdf }}$

ICAN \& RCSLT (2018) Bercow Ten years on. London: ICAN. Justice LM (2004) Creating language-rich preschool classroom environments. Teaching Exceptional Children, 37(2): 36-44. 
Justice LM, Skibbe LE, McGinty AS, Piasta SB, and Petrill S (2011) Feasibility, efficacy, and social validity of home-based storybook reading intervention for children with language impairment. Journal of Speech, Language, and Hearing Research, 54(2): 523-538.

Law J, Dockrell J, Williams K, and Seeff B (2004) Comparing specialist early years provision for speech and language impaired children with mainstream nursery provision in the UK - An application of the Early Childhood Environment Rating scale (ECERS). Child: Care Health and Development, 30(2): 177-184.

Leyden J, Stackhouse J, and Szczerbinski M (2011) Implementing a whole school approach to support speech, language and communication: Perceptions of key staff. Child Language Teaching and Therapy, 27(2): 203-222.

LoCasale-Crouch J, Konold T, Pianta R, Howes C, Burchinal M, Bryant D, ... and Barbarin OA (2007) Observed classroom quality profiles in state-funded prekindergarten programs and associations with teacher, program, and classroom characteristics. Early Childhood Research Quarterly, 22(1): 3-17.

Long, A. C., Sanetti, L. M. H., Collier-Meek, M. A., Gallucci, J., Altschaefl, M., \& Kratochwill, T. R. (2016). An exploratory investigation of teachers' intervention planning and perceived implementation barriers. Journal of school psychology, 55, 1-26.

Mashburn AJ, Pianta RC, Hamre BK, Downer JT, Barbarin OA, Bryant D, ... and Howes C (2008) Measures of classroom quality in prekindergarten and children's development of academic, language, and social skills. Child development, 79(3): 732-749. 
Mashburn AJ, Justice LM, Downer JT, and Pianta RC (2009) Peer effects on children's language achievement during pre-kindergarten. Child development, 80(3): 686702.

May, C., Finch, T., Mair, F., Ballini, L., Dowrick, C., Eccles, M., . . Heaven, B. (2007). Understanding the implementation of complex interventions in health care: the normalization process model. BMC Health Services Research, 7, 7. doi:10.1186/1472-6963-7-148

Michie, S., van Stralen, M., \& West, R. (2011). The behaviour change wheel: A new method for characterising and designing behaviour change interventions. Implementation Science, 6(1), 42. doi:10.1186/1748-5908-6-42

Michie, S., Atkins, L., \& West, R. (2014). The Behaviour Change Wheel: A Guide to Designing Interventions. England: Silverback Publishing.

Nagy W, and Townsend D (2012) Words as tools: Learning academic vocabulary as language acquisition. Reading Research Quarterly, 47(1): 91-108.

Pianta R, La Paro K, Hamre B, Mashburn A, and Locastle-Crouch J (2007) The Classroom Assessment Scoring System. US: Paul H Brookes Pub Co.

Schlager M.S. \& Fusco J. (2003) Teacher Professional Development, Technology, and Communities of Practice: Are We Putting the Cart Before the Horse?, The Information Society, 19:3, 203-220, DOI: $\underline{\text { 10.1080/01972240309464 }}$

Squires, J. E., Aloisio, L. D., Grimshaw, J. M., Bashir, K., Dorrance, K., Coughlin, M., . . . Graham, I. D. (2019). Attributes of context relevant to healthcare professionals' use of research evidence in clinical practice: a multi-study analysis. Implementation Science, 14(1), 52. doi:10.1186/s13012-019-0900-8 
Stackhouse J, Szczerbinski M, and Leyden J (2009) I CAN's Primary Talk training and accreditation package: An evaluation of the pilot phase in one local authority. Research Report. London: I CAN.

Turnbull KP, Anthony AB, Justice L, and Bowles R (2009) Preschoolers' exposure to language stimulation in classrooms serving at-risk children: The contribution of group size and activity context. Early Education and Development, 20(1): 53-79.

Vivash J, Dockrell J, and Lee F (2018) The re-alignment of educational psychologists in supporting primary schools to enhance provision for children with speech, language and communication needs. Educational \& Child Psychology: Special Issue September 43-59.

Wasik BA, and Bond MA (2001) Beyond the pages of a book: Interactive book reading and language development in preschool classrooms. Journal of educational psychology, 93(2): 243-250.

Whorrall J, and Cabell SQ (2016) Supporting children's oral language development in the preschool classroom. Early Childhood Education Journal, 44(4): 335-341.

Wright TS, and Neuman SB (2014) Paucity and disparity in kindergarten oral vocabulary instruction. Journal of Literacy Research, 46(3): 330-357. 


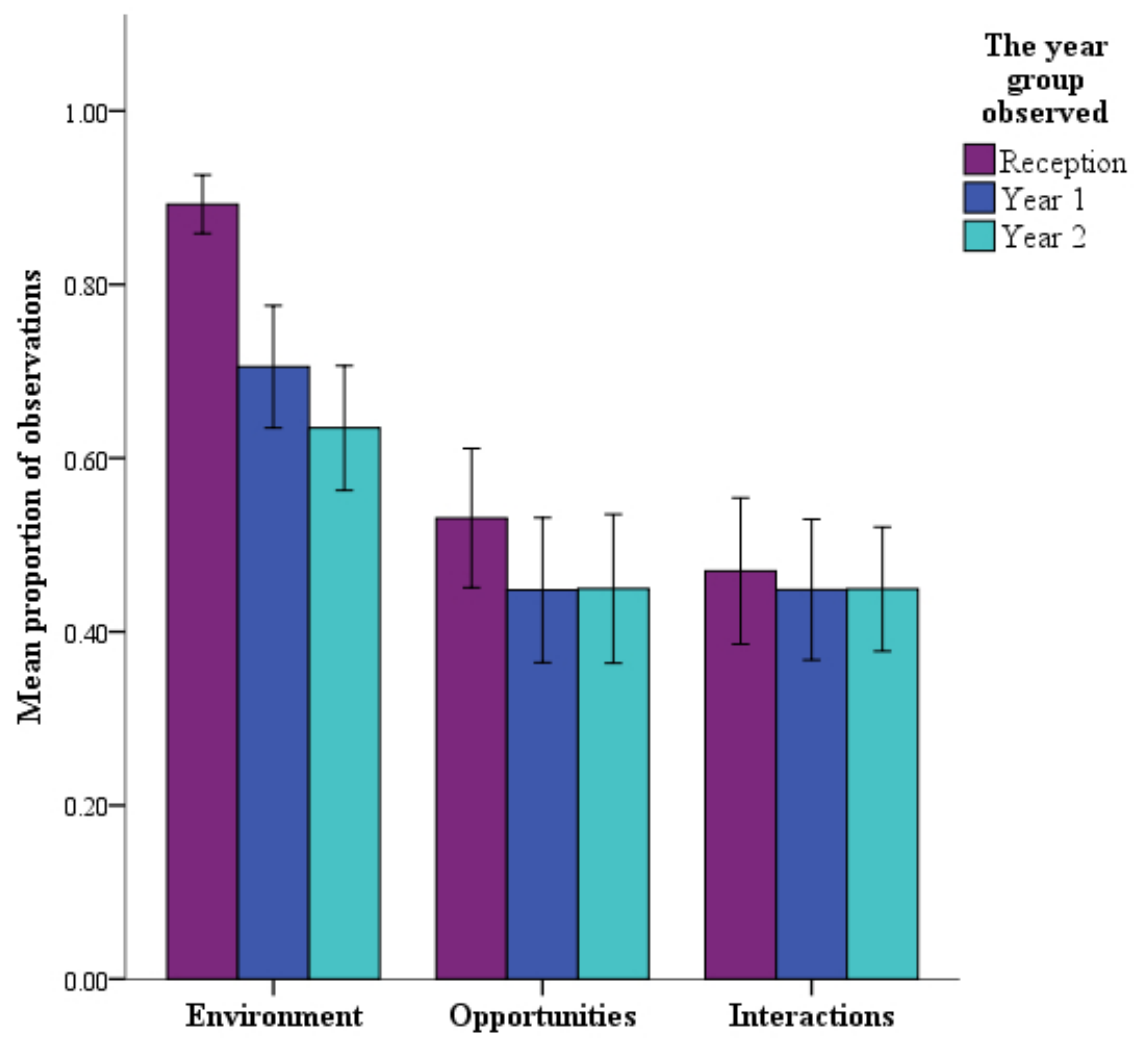

Figure 1. Mean (+/- SD) Proportion Score for each dimension of the CSCOT for the Three Year Groups 
Appendix 1: Questions from the teacher questionnaire.

What is the most useful language learning area to observe for teachers and teaching staff in your/other's school for developing knowledge of oral language and communication skills?

$\square$ Language Learning Environment

$\square$ Language Learning Interactions

$\square$ Language Learning Opportunities

Why?

Since the observations, do you use/plan to use any new programmes to promote oral language and communication skills for all children in your classroom?

\begin{tabular}{l|l} 
Yes & No
\end{tabular}

Since the observations, do you think that teachers and teaching staff require any further training on oral language and communication skills and needs? Please circle

\begin{tabular}{l|l} 
Yes & No
\end{tabular}

Since the observations, how confident do you feel discussing children with speech, language and communication needs with speech and language therapists? Please rate on a scale of 1-6 with $1=$ 'Not at all' to $6=$ 'Extremely'

1

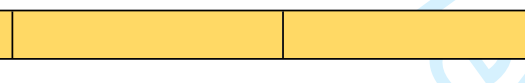

6

How did you find arranging and completing the observations for this project? (e.g. ease of logistics to arrange observations, having adequate time to complete them, teachers/teaching staff being comfortable being observed, understanding how to mark items etc.) Please specify

When observing different year groups, were there any differences for certain language learning areas (environment/opportunities/ interactions) or specific items? If so, what were they? Please specify 
Were there any items which you felt were difficult/impractical to implement in your classroom? Why do you think this is? Please specify

Please share the key elements of your action plan created as a result of using the observation tool. This can include either general language learning areas or specific items on the CSCOT. It can also be plans for specific year groups, all year groups, using some practices from one year group to improve another's practices and anything else you think will be useful. 